DOE G 440.1-2

06-26-97

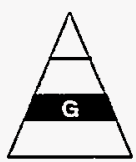

\title{
CONSTRUCTION SAFETY MANAGEMENT GUIDE for use with DOE ORDER 440.1
}

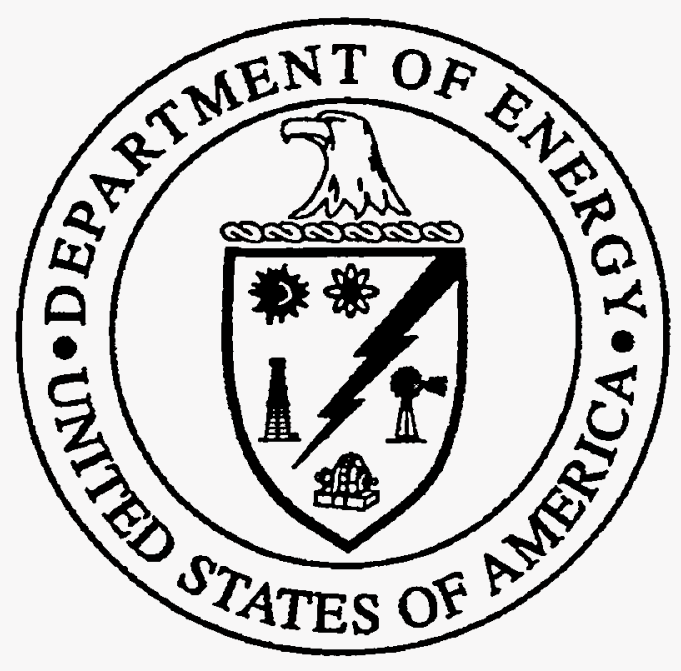

RECEIVED JuL $1^{4} 1997$ $08 T 1$

\section{OFFICE OF WORKER HEALTH AND SAFETY}




\section{DISCLAIMIER}

Portions of this document may be illegible in electronic image products. Images are produced from the best available original document. 


\section{CONTENTS}

\section{Page}

FOREWORD iii

1. INTRODUCTION $\ldots \ldots \ldots \ldots \ldots \ldots \ldots \ldots \ldots \ldots \ldots \ldots \ldots \ldots \ldots \ldots \ldots \ldots$

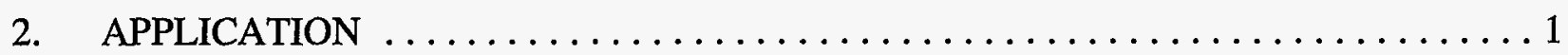

3. GENERAL INFORMATION $\ldots \ldots \ldots \ldots \ldots \ldots \ldots \ldots \ldots \ldots \ldots \ldots \ldots \ldots \ldots \ldots \ldots \ldots$

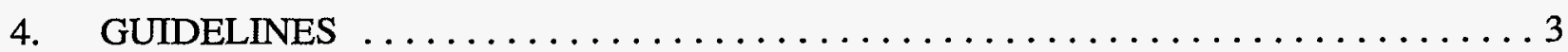

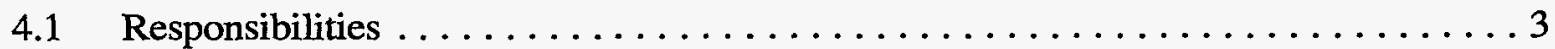

4.2 Coordination of Construction and M\&O Safety and Health Requirements .. 4

4.3 Construction Contractor Evaluations ................... 4

4.4 Construction Project Acquisition Documents ............... 6

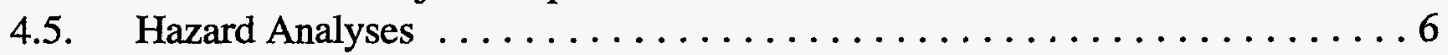

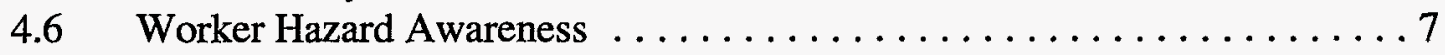

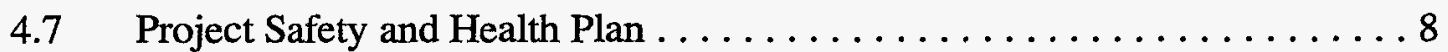

4.8 Inspections and Hazard Abatement $\ldots \ldots \ldots \ldots \ldots \ldots \ldots \ldots \ldots$

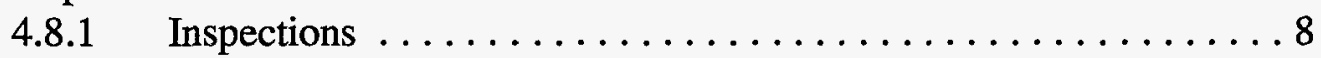

4.8.2 Hazard Abatement $\ldots \ldots \ldots \ldots \ldots \ldots \ldots \ldots \ldots \ldots$

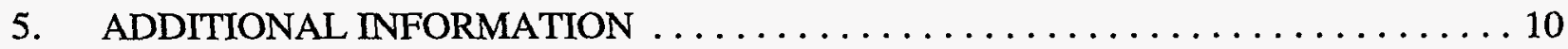




\section{FOREWORD}

1. This Department of Energy (DOE) Guide is approved for use by the Office of Environment, Safety and Health and is available for use by all DOE components and their contractors.

2. Beneficial comments (recommendations, additions, and deletions) and any pertinent data that may improve this document should be sent to the Director, DOE Office for Worker Health and Safety (EH-5), U.S. Department of Energy, Washington, D.C. 20585, by letter or by sending the self-addressed Standardization Document Improvement Proposal (DOE F 1300.3).

3. This Guide is intended to identify acceptable methods for implementing the provisions of DOE Order 440.1. 
06-26-97

\section{CONSTRUCTION SAFETY MANAGEMENT}

\section{INTRODUCTION}

\section{DOE Order (DOE O) 440.1, WORKER PROTECTION MANAGEMENT FOR DOE}

FEDERAL AND CONTRACTOR EMPLOYEES, establishes the framework for an effective worker protection program to reduce or eliminate accidental losses, injuries, and illnesses by providing workers with places of employment free of recognized hazards. In addition to prescribing program requirements applicable to all activities performed by DOE and its contractors, DOE O 440.1 provides specific requirements applicable only to construction activities.

The intent of these construction-specific requirements is to compel the proactive management of construction safety on a project-by-project basis and, to the greatest extent possible, integrate the management of safety and health, both in terms of project personnel and management methodologies, with the management of the other primary elements of construction project performance: quality, cost and schedule.

\section{APPLICATION}

The construction-specific provisions of DOE O 440.1 apply to all construction projects above the monetary threshold established by the Davis-Bacon Act (40 U.S.C. 276a) at Government-owned or -leased facilities upon which the contract clause "Safety and Health (Government Owned or Leased Facility)" applies. The rationale for reference to the Davis-Bacon Act is that there exists at each DOE site a committee with the responsibility to review proposed construction-like activities above a given monetary threshold (currently $\$ 2,000$ ) to determine applicability of wage rates prescribed by the Act (i.e., which activities are construction and which are not). This provides a formal (and already existing) mechanism to determine which site activities must comply 
with these construction safety provisions and which do not (operations, maintenance, and other site services).

It should be noted, however, that some activities that formally meet the definition of construction provided in the DOE Glossary may not necessarily be deemed "construction" by a site's DavisBacon Committee. For example, there exists legal (and disputed) precedent supporting the argument that demolition activities not followed up by subsequent construction do not represent "public works" within the scope of the Davis-Bacon Act. It is not the intent of the Order to "weigh-in" on this dispute in any way because a directive for construction safety is an inappropriate mechanism to decide which work force and wage rate will prevail on particular site activities. It is the intent, however, that the Order be applied to demolition activities because the applicable safety standards for construction, 29 CFR 1926, specifically address demolition activities.

The application of these requirements to sites where the referenced contract clause is in force effectively exempts the Power Marketing Administrations as well as construction activities that are DOE funded but that are performed on state or private property outside the jurisdictional auspices of the Department (e.g., research facilities built on university campuses funded by DOE grants).

\section{GENERAL INFORMATION}

It is the intent of the Order's construction-specific requirements to compel proactive management of construction safety on all construction projects through:

- Systematic and timely evaluation of project hazards;

- Planning and selection of appropriate and effective protective measures;

- Informing workers of all foreseeable hazards and required protective measures;

- An active regimen of workplace inspections and prompt abatement of identified hazards. 
Further, it is the intent of the Order to integrate the safety and health requirements of the Order, to the greatest extent practicable, with the required activities of the project management team otherwise necessary to ensure compliance with the cost, quality, and schedule requirements of the project. For example, the documentation requirements of the Order should be integrated, to the greatest degree possible, with existing project documentation requirements (e.g., daily logs of construction), and when possible, the required job site inspections should be done, consistent with project staff qualifications, concurrent with other onsite quality assurance activities.

Though the program requirements of the Order may seem overly burdensome or costly on small construction projects, a "graded approach" is inherent to the implementation of its requirements. Specifically, the "backbone" of the Order's programmatic requirements is a hazard analysis for each construction operation presenting hazards not previously experienced or performed by a different subcontractor. By nature, the more complex and costly a project is, the more such operations are involved, and accordingly, the greater the amount of required pre-job planning.

Also, the construction safety and health program requirements of the Order (Hazard Analyses, Worker Training, Project Safety and Health Plan) need not duplicate those prescribed by the OSHA standard for Hazardous Waste Operations and Emergency Response [refer to Title 29 CFR 1926.65(b)].

\section{GUIDELINES}

\subsection{Responsibilities}

The Order provides considerable flexibility with regard to who on the project management team (i.e., the DOE project manager, his or her support staff, as well as the construction manager) should enforce and oversee safety and health performance of the construction contractor. However, these respective responsibilities must be delineated in written 
agreements or implementing instructions to ensure that the responsible parties are aware of and accept their respective responsibilities.

\subsection{Coordination of Construction and M\&O Safety and Health Requirements}

The Order requires DOE to review safety and health program elements developed by the host for site maintenance and operation activities to determine suitability and cost effectiveness on site construction projects. The intent of this requirement is twofold. First, in instances where the host and construction contractors mutually expose their employees to common hazards, it is probably both desirable and cost effective to mandate construction contractor adherence to sitewide $\mathrm{OSH}$ policies and procedures. However, there are also instances where mandated compliance by the construction contractor with host OSH program requirements that go beyond applicable DOE adopted OSH standards or are poorly suited to construction will have little, if any, positive impact on safety and health but will adversely affect project cost and schedule.

\subsection{Construction Contractor Evaluations}

The intent of the Order is to ensure the development and implementation at each site of a system by which the effectiveness of construction contractors' safety and health programs are systematically and objectively evaluated and to ensure that these evaluations are subsequently used in the determination of bidder responsibility on future projects. It should be noted that the system envisioned by the Order does not specifically call for, nor encourage, a prequalification of prospective bidders based upon empirically derived indicators of past safety and health performance such as Workers' Compensation Experience Modifier Rates (EMRs) or incidence rates derived from a contractor's OSHA 200 Log (a required listing of recordable injuries and illnesses). 
The distinctions between these systems need to be made clear. Whereas the former provides a direct (and fair) measure of a contractor's recent and relevant safety and health performance [and is accordingly prescribed by Federal Acquisition Regulation (FAR) 36.201 for fixed-price construction], the use of performance indicators such as the EMR and incidence rates as the sole arbiter of prospective safety and health performance is problematic for several reasons.

The EMR is inherently biased against companies with small payrolls (i.e., small business) in that a single catastrophic loss constitutes a larger percentage of annual payroll (upon which premiums are based) than it would for a large company. Moreover, it is based on performance from two to four years ago as opposed to current performance and, therefore, will not reflect recent safety and health program improvements, regardless of magnitude.

With respect to the use of incidence rates as a prequalification criterion, history has shown clearly that the mere use of these rates for such purposes has led, in and of itself, to their marked improvement (without necessarily an improvement in true performance). Accordingly, it is doubtful whether sole reliance on such criteria fulfills the fundamental credo of Federal contracting: fair and open competition.

This is not to say that contractor prequalification does not have a place in the management of safety and health on DOE construction projects, but that is a distinctly different process than making a determination of bidder responsibility based upon past performance. Generally, prequalification should be reserved for use on highly complex or hazardous projects for which the need for specific safety and health experience and qualifications (and the resulting restriction of competition) can be clearly demonstrated (refer to FAR 9.202). 


\subsection{Construction Project Acquisition Documents}

It is intended that the safety and health requirements of the Order be clearly communicated to the construction contractor through the development and incorporation of appropriate contract language in the project acquisition documents and not simply by reference. In most cases, this can be best achieved through local development and use of contract "boilerplate" safety and health provisions, which allow for insertion of project-specific requirements when needed (e.g., dedicated project OSH staff, applicable host contractor safety and health requirements).

\subsection{Hazard Analyses}

The intent of the required hazard analyses is to compel a proactive and systematic evaluation of project hazards, timely planning of abatement strategies, and effective, relevant employee training. This may be achieved in a variety of ways. Contract provisions may call for a complete hazard evaluation process to be performed by the construction contractor, or the project specifications may provide checklists or outlines that fulfill any portion (or all) of the hazard analysis requirements for later completion and implementation by the construction contractor.

Regardless of the procedural means chosen, a means to identify project operations requiring hazard analyses must be provided prior to project commencement. This ensures a means to "tie" those operations to the project schedule, allowing for their timely completion and providing a means for the project manager to assess whether adequate preparations have been made (i.e., abatement methods chosen/designed, professional staff in place, employee training accomplished) prior to commencement of each project phase. 
06-26-97

The complexity and degree of effort associated with the development of these hazard analyses should not be confused with that required for the preparation of "Safety Analysis Reports," extensive evaluations of the safe operating parameters of DOE nuclear facilities. As is common across the construction industry, these analyses commonly require from several lines to several pages for each project operation (generally in tabular form), depending on the nature of work being addressed. Complexity is not the key; what is essential is the identification and approval, in advance, of the actual work practices and protective measures to be employed. This helps to ensure a safe work environment from the outset on each construction operation and to avoid the often lengthy and costly disputes that occur as a job is delayed while unresolved safety issues are resolved.

By virtue of the fact that the approval authority for these analyses is the project manager or his or her designee, the format, level of detail, and required complexity are left to his or her discretion. However, it may be desirable within local implementing instructions to formalize the procedural means for accomplishing these hazard analyses, including such issues as format and level of required detail.

\subsection{Worker Hazard Awareness}

Beyond the specific training requirements contained within-DOE-prescribed worker protection Standards (e.g., 29 CFR 1926), the Order does not specify curricula or duration of required employee worker safety and health training but emphasizes the need to formally communicate information concerning foreseeable project hazards and required protective measures prior to commencement of work on the affected construction operation. The approved hazard analysis for the respective construction operation is ideally suited to communicate this information to the worker. 


\subsection{Project Safety and Health Plan}

To avoid confusion, it was decided during the development of the Order to use the word "program" to describe the safety and health requirements of the Order and the word "plan" to describe the contractor's project-specific written proposal to implement these requirements.

It was also decided to let the hazard analyses become "stand-alone" requirements separate from the safety and health plan in that, once approved, an acceptable safety and health plan could possibly be used, with little or no modification, by a construction contractor on future projects. This could help lessen the initial paperwork requirements that may unnecessarily delay a project's start and also reduce the possibility that pressures to "break ground" would result in a hasty and incomplete evaluation of project hazards.

\subsection{Inspections and Hazard Abatement}

\subsubsection{Inspections}

DOE O 440.1 clarifies the requirement of 29 CFR 1926.20(b)(2) which calls for "frequent and regular inspections of the job sites" by each employer (i.e., the construction contractor and all subcontractors). Consistent with requirements of the Federal Acquisition Regulation, which call for the onsite presence of a superintendent during the performance of any project work activities (see FAR 36.506 and 36.519 for fixed-price and cost reimbursement construction, respectively), the Order calls for daily inspections of the job site by the construction contractor during periods of active work. 
It should be noted that the frequency of required job site inspections by the project manager or his or her designee (i.e., support staff or construction manager) is given as "frequent and regular" as opposed to any specific frequency (such as weekly or monthly). The desired frequency of project inspections, consistent with project size, complexity, and risk level should be addressed within local implementation guidance.

It should be noted that it is the intent of the Order to allow for the required safety and health inspections of all parties (as well as the accompanying documentation) to be accomplished concurrent with their other onsite activities. There is no specific requirement for standalone project safety and health inspections by the safety and health staffs of the construction or project managers if project personnel have the requisite skills to perform these functions. However, in cases where project staff lack the necessary skills or experience or where particularly hazardous or complex work is ongoing, it may be that these requirements are best fulfilled by safety and health professionals duly tasked by the construction or project managers.

\subsubsection{Hazard Abatement}

Generally, it is both desirable and practical to demand immediate abatement of identified hazards on a construction project because they are mostly of the construction contractor's making (and contract terms generally call for immediate abatement with provisions for uncompensated work stoppages if this is not achieved.) However, there are instances where it may be either impossible or impractical to demand immediate abatement of a hazard or where abatement of a particular hazard may fall outside of project scope.

The Order provides specific steps that should be taken in such instances. It is not, however, the intent of the Order to provide a vehicle or a requirement for priority treatment of abatement actions outside of project scope (with project funds) above other pending, and possibly more crucial, site abatement actions. 


\section{ADDITIONAL INFORMATION}

For site-specific questions concerning the implementation of DOE O 440.1, contact your DOE Operations Office's or DOE contractor organization's Worker Protection Manager.

EH-51 also develops and disseminates interpretations of DOE worker protection Standards. A toll-free response line has been established to address requests for interpretations. Precedented requests for interpretations are maintained in a database and can usually be addressed in a matter of minutes. Unprecedented requests are addressed with a written response, usually within 20 working days. The Standards Interpretations Response Line telephone number is 1-800-2928061. Hours of operation are 8 a.m. to 4 p.m. (Eastern time) Monday through Friday.

For additional information about the DOE Construction Safety Management Program or concerning implementation of the construction safety requirements of DOE O 440.1, contact Pat Finn in the Office for Worker Safety and Health (EH-51) at (301) 903-9876. 